\title{
Assistance to the puerperium and the construction of a flow chart for nursing consultation
}

Lilian Puglas da Silva 1

D https://orcid.org/0000-0001-7102-2862

Laura Menezes da Silveira 2

iD https://orcid.org/0000-0002-2397-2553

Tatiane de Jesus Martins Mendes 3

https://orcid.org/0000-0001-5961-5091

Angelita Maria Stabile 4

https://orcid.org/0000-0002-3371-7038

1-4 Escola de Enfermagem de Ribeirão Preto. Universidade de São Paulo. Av. Bandeirantes, 3900. Ribeirão Preto, SP, Brasil. CEP: 14.040-902. E-mail: lipuglas@yahoo.com.br

\begin{abstract}
Objectives: to identify the main complaints and problems presented by women in the puerperium during nursing consultations and create a care flow chart.

Methods: descriptive, cross-sectional exploratory study with quantitative treatment of data conducted in a private hospital in Brazil, with a sample of 114 women.

Results: of the puerperal women evaluated, $57.9 \%$ were primiparous and $66.7 \%$ reported not having received guidance about the puerperal period. Cesarean sections occurred in $89.5 \%$ of the sample, and $80.7 \%$ of the women presented difficulties inherent to the care given to the newborn or self-care. All mothers were breastfeeding and $42.1 \%$ of them reported difficulties in this process. Among breast complications, 30.7\% corresponded to fissures. In view of the needs observed in the nursing consultation, women received guidelines from the nurses, and were referred for specialized evaluation when pertinent.

Conclusions: it was observed that problems and complaints presented by women in the puerperium were related with care to the newborn, breastfeeding, emotional state and family support. Health professionals who give puerperal consultations should consider the sociocultural environment in which the puerperal woman is inserted in order to link their beliefs with science.
\end{abstract}

Key words Maternal and child health, Nursing care, Puerperium, Nursing consultation 


\section{Introduction}

Puerperium is a phase of the pregnancy-puerperium cycle marked by intense changes in the biological, psychological and sociocultural dimensions. It is a period in which the mother-child bond is formed and the intercommunication network within the family is restructured.1,2 It starts after the placenta is delivered, which is the moment when the mother is disconnected from the baby and herbody returns to its pre-pregnancy condition. ${ }^{3}$ During this period, there is a need for individualized care to meet the needs of women, newborns (NBs) and the family in a comprehensive way, with respect to their sociocultural environment, so as to promote child health and well-being. 4

Currently, fragmentation in the care offered to women is noticed, and this can impair the quality of the care provided. Over the years, public health programs and policies have been created in order to ensure quality care with focus on comprehensiveness, particularly the Program for Comprehensive Care to Women's Health (PCCWH) in 1983 and the National Policy of Comprehensive Care to Women's Health (NPCCWH) in 2004.5

The NPCCWH advocated to contribute to women's health in all life cycles, from adolescence to menopause, in order to contemplate the areas of mental and gender health, chronic-degenerative diseases and gynecological cancers. This policy makes it possible that women from different population groups (black, detainees, indigenous, rural and homosexuals) benefit from advances in the field of sexual and reproductive rights, obstetric care, family planning, care for unsafe abortion, and fight against domestic and sexual violence. 5

Despite the advances in the implementation of these policies, strengthening is still necessary because the puerperium is a period when women are more vulnerable to complications when compared to other phases of the pregnancy cycle. ${ }^{6}$ This is often the moment woman has less contact with the health teams, because while a minimum of six consultations are recommended during prenatal care, only one puerperal consultation is recommended between the $7^{\text {th }}$ and $10^{\text {th }}$ day after delivery. ${ }^{7}$

Among the professionals who assist women during the puerperium, nurses stand out as professionals who were trained to understand puerperal changes. When carrying out nursing consultations, nurses must be able to identify and prevent complications, provide guidance and encourage women to practice self-care and to provide care to the newborn. Furthermore, nurses can request evaluations by other professionals whenever necessary. 6,8

In this sense, nurses act as facilitators for the patients to gain autonomy to face periods of vulnerability, such as the pregnancy-puerperium cycle. ${ }^{8-10}$ The assistance offered to women during the pregnancy-puerperium cycle begins in prenatal consultations and covers childbirth and the puerperium, with educational actions for each stage of the cycle, providing safety and health during this period. 9,11 It is also noteworthy that nursing consultations in the puerperium have the function of contributing to lower maternal morbidity and mortality rates through the encouragement of breastfeeding, provision of guidance on family planning and postnatal care to the mother-child binomial. ${ }^{4}$ However, the number of women who attend puerperal consultations in health facilities is very low. 12

In view of the benefits of nursing consultations in the puerperium, $4,7-8,10,12-13$ it is believed that recognizing the main needs of women in this period and offering systematic assistance can bring benefits to the mother-child binomial, such asearly identification and treatment of specific pathologies of the cycle. In this context, the purpose of this study was to identify the main complaints and problems of women seen in a private health institution during nursing consultations in the puerperium and develop a systematic care flow for women and newborns.

\section{Methods}

This is a descriptive, exploratory study, with quantitative treatment of data. The study was carried out in a medium-size private reference hospital in the region, established in the coutryside of São Paulo, linked to 28 supplementary health insurance companies, and with a total of 113 beds. The maternity hospital had 16 obstetric beds, three beds for a pathological nursery and a milking room for collecting human milk. It has a multidisciplinary team composed of two obstetric nurses, 25 nursing technicians, a speech therapist, and an obstetric and pediatric medical team. On average, 100 newborns are born per month, mostly by cesarean section. The average hospital stay is 48 hours after cesarean section and 24 hours after normal delivery.

Data collection took place from October to December 2016. All postpartum women aged $\geq 18$ years, who gave birth at the institution and returned to the puerperal consultation during the abovementioned period, were included in the sample. The mothers of NBs who remained hospitalized after discharge were excluded from the study.

Puerperal consultations were scheduled between 
the $7^{\text {th }}$ and $10^{\text {th }}$ day after delivery, according to the recommendations of the Ministry of Health $(\mathrm{MOH}),{ }^{7}$ and also because this is a favorable period to identify, prevent and treat possible pathological changes in the mother-child binomial and also encourage exclusive breastfeeding. The appointment occurred at the moment of hospital discharge and women were invited to participate in the research on the day of the consultation. To obtain the data, during the puerperal nursing consultation, a form was prepared by the researcher addressing questions on sociodemographic data, prenatal care, childbirth care, puerperal care, physical examination of the NB and physical examination of the puerperal woman. The physical examination followed a script that sought to identify the main complaints and problems presented by women in the puerperium that were seen at the consultation according to the MOH's Technical Manual of Prenatal and Puerperal Care. 7

Data were analyzed and described through total and relative frequency values in the case of nominal or categorical variables, and using measures of central tendency in the case of continuous variables. These analyses were made with the aid of the Statistical Package for the Social Sciences (SPSS) version 17.0. To check for possible associations between categorical variables, the Pearson's chisquare test or Fisher's exact test (when relevant) were used. The Mann-Whitney test was used to analyze the numerical variables (due to the nonnormal distribution of data). For the criterion of statistical significance in these tests, a value of $p<0.05$ was adopted. The study was approved by a Research Ethics Committee (REC), under CAAE 54337416.2 .0000 .5393 .

\section{Results}

During the period of this study, 295 pregnant women gave birth at the institution. Of this total, 12 were excluded based on the established criteria, thus totaling 283 women eligible to participate in this research, of which 114 returned to the consultation and accepted to participate in the study.

The women were on average 29 years old, with $65(57.1 \%)$ of them aged between 21 and 30 years and $44(38.6 \%)$ between 31 and 40 years. The sociodemographic characteristics of the women attended is shown in Table 1.

The description of the clinical-obstetric profile points out that: 66 (57.9\%) women were primiparous and $48(42.1 \%)$ multiparous; 111 (97.3\%) had attended six or more prenatal consultations and the average was eight consultations; 108 (94.8\%) women had gestational age at delivery between 37 and 41 weeks and six (5.2\%) had premature births, that is, had gestational age of less than 37 weeks at delivery; and $102(89.5 \%)$ women underwent cesarean section and $12(10.5 \%)$ had vaginal delivery.

The data in this study, as described in Table 2, show that $114(100 \%)$ of the women were breastfeeding: $92(80.7 \%)$ practiced exclusive breastfeeding and $22(19.3 \%)$ used complementation while breastfeeding. Among the interviewees, 66 (57.9\%) did not have difficulties in breastfeeding and 48 $(42.1 \%)$ had difficulties in relation to the breastfeeding technique, mainly regarding the "correct latch".

Association tests were carried out between the type of breastfeeding (exclusive or partial/mixed) and the sociodemographic variables: age $(p=0.302)$, marital status $(p=0.273)$, education $(p=0.590)$, occupation $(p=0.758)$, religion $(p=0.607)$, and family income $(p=0.742)$. There was no statistical association between these variables.

Likewise, no statistically significant associations were found between the type of breastfeeding (exclusive or partial/mixed) and complaints related to breastfeeding ( $p=0.927)$; presence of changes in the breasts $(p=0.740)$; type of delivery $(p=0.119)$; and number of prenatal consultations $(p=0.302)$.

Additionally, the relationship between difficulty in breastfeeding and the number of prenatal consultations $(p=0.605)$, type of delivery $(p=0.759)$, complaints about breastfeeding $(p<0.001)$, and presence of changes in the breasts $(p<0.001)$ was also investigated, and statistically significant results were seen in the case of the last two.

The NBs were evaluated at the nursing consultation for characteristics related to birth and information collected during the physical examination, as described in Table 3.

The average weight of the newborns was 3,189 grams on the day of birth, with seven $(6.1 \%)$ weighing between 1,500 and 2,500 grams, 103 $(90.4 \%)$ between 2,501 and 4,000 grams, and four (3.5\%) more than 4,000 grams. The average weight on the day of the puerperal consultation was 3,136 grams. Among the NBs evaluated, 47 (41.2\%) gained weight, $62(54.4 \%)$ had lost up to $10 \%$ of birth weight, and five (4.4\%) had lost more than $10 \%$ of birth weight. Interestingly, the mothers of babies who lost more than $10 \%$ of birth weight did not have any change in the breast, difficulty in breastfeeding or complaints.

Regarding the characteristics of birth, there was a predominance of the practice of rooming-in and 
Table 1

Sociodemographic characteristics of women assisted according to marital status, education, occupation and religion $(n=114)$. Franca, State of São Paulo (SP), Brazil, 2016.

\begin{tabular}{|c|c|c|}
\hline Variables & $\mathbf{N}$ & $\%$ \\
\hline \multicolumn{3}{|l|}{ Age (years) } \\
\hline $0-20$ & 3 & 2.6 \\
\hline $21-30$ & 65 & 57.1 \\
\hline $31-40$ & 44 & 38.6 \\
\hline 41 & 2 & 1.7 \\
\hline \multicolumn{3}{|l|}{ Marital status } \\
\hline Married/Consensual union & 111 & 88.6 \\
\hline Single & 13 & 11.4 \\
\hline \multicolumn{3}{|l|}{ Education (years of schooling) } \\
\hline Elementary School (0 to 9 years) & 9 & 7.9 \\
\hline High School ( $\geq 10$ up to 12 years) & 47 & 41.2 \\
\hline Higher Education ( $\geq 13$ years) & 58 & 50.9 \\
\hline \multicolumn{3}{|l|}{ Occupation } \\
\hline Housewife & 18 & 15.8 \\
\hline Employed & 96 & 84.2 \\
\hline \multicolumn{3}{|l|}{ Religion } \\
\hline Catholicism & 75 & 65.8 \\
\hline Evangelical & 26 & 22.8 \\
\hline Spiritist & 13 & 11.4 \\
\hline \multicolumn{3}{|l|}{ Family income } \\
\hline $\mathrm{R} \$ 2,000.00$ & 39 & 34.2 \\
\hline$R \$ 3,000.00$ to $R \$ 4,000.00$ & 46 & 40.4 \\
\hline$>\mathrm{R} \$ 4,000.00$ & 29 & 25.4 \\
\hline
\end{tabular}

Table 2

Description of characteristics, difficulties and complaints related to breastfeeding, physical examination and breast changes, types, characteristics and changes in the surgical incision $(n=114)$. Franca, State of São Paulo (SP), Brazil, 2016.

\begin{tabular}{lcc}
\hline Variables & N & $\%$ \\
\hline Exclusive breastfeeding & & \\
Yes & 92 & 80.7 \\
No & 22 & 19.3 \\
Difficulties in breastfeeding & & \\
Yes & 48 & 42.1 \\
No & 66 & 57.9 \\
Complaints about the breasts & & 50.9 \\
None & 58 & 46.5 \\
Pain & 53 & 2.6 \\
Low quantity of milk & 3 & 60.5 \\
Physical examination of the breasts & & 39.5 \\
Normal & 69 & 2.6 \\
Changed & 45 & 36.8 \\
Change type & & continue \\
Breast engorgement & 3 & \\
Nipple trauma & 42 & \\
\hline
\end{tabular}

* The " $\mathrm{N}$ " considered for analysis of the type of nipple trauma was 42 , that is, a percentage in relation tothe women with trauma; **The " $\mathrm{N}$ " considered for analysis of the type of surgical incision was 113 , because one of the women did not have any incision; $* * *$ The " $\mathrm{N}$ " considered for analysis of the type of change seen in the surgical incision was 17 , that is, only the women who had changes. 
Description of characteristics, difficulties and complaints related to breastfeeding, physical examination and breast changes, types, characteristics and changes in the surgical incision $(n=114)$. Franca, State of São Paulo (SP), Brazil, 2016.

\begin{tabular}{lcc}
\hline Variables & N & $\%$ \\
\hline Type of trauma* & 5 & 4.4 \\
Erythema & 35 & 30.7 \\
$\quad$ Cracks & 2 & 1.8 \\
$\quad$ Bruises & 102 & 90.3 \\
Surgical incision & 11 & 9.7 \\
$\quad$ Cesarean section & & 84.9 \\
Episiotomy & 96 & 15.1 \\
Evaluation of the surgical incision & 17 & 41.2 \\
$\quad$ Normal & & 23.6 \\
Changed & 7 & 17.6 \\
Type of change seen in the surgical incision*** & 17.6 \\
Hyperemia & 4 & 17 \\
$\quad$ Secretion & 3 & 3 \\
$\quad$ Hyperemia and secretion & 3 & \\
\hline
\end{tabular}

* The " $N$ " considered for analysis of the type of nipple trauma was 42 , that is, a percentage in relation tothe women with trauma; **The " $\mathrm{N}$ " considered for analysis of the type of surgical incision was 113, because one of the women did not have any incision; $* * *$ The " $N$ " considered for analysis of the type of change seen in the surgical incision was 17 , that is, only the women who had changes.

Table 3

Description of the newborns' characteristics in relation to birth and physical examination of the skin, fall and changes of the umbilical stump, changes $(n=114)$. Franca, State of São Paulo (SP), Brazil, 2016.

\begin{tabular}{|c|c|c|}
\hline Variables & $\mathbf{N}$ & $\%$ \\
\hline \multicolumn{3}{|l|}{ Gestational age at birth (weeks) } \\
\hline Pre-term $(<37)$ & 6 & 5.3 \\
\hline Term $(\geq 37-41)$ & 108 & 94.7 \\
\hline \multicolumn{3}{|l|}{ Immediate rooming-in } \\
\hline Yes & 105 & 92.1 \\
\hline No & 9 & 7.9 \\
\hline \multicolumn{3}{|c|}{ Reason for non-accommodation in rooming-in } \\
\hline Transient tachypnea of the NB & 7 & 6.1 \\
\hline Neonatal hypothermia & 1 & 0.9 \\
\hline Maternal instability & 1 & 0.9 \\
\hline \multicolumn{3}{|l|}{ Type of breastfeeding } \\
\hline Exclusive & 92 & 80.7 \\
\hline Partial or mixed & 22 & 19.3 \\
\hline \multicolumn{3}{|l|}{ Skin } \\
\hline Flushed & 104 & 91.2 \\
\hline Suggestive of jaundice & 10 & 8.8 \\
\hline \multicolumn{3}{|l|}{ Fall of the umbilical stump } \\
\hline Yes & 41 & 36.0 \\
\hline No & 73 & 64.0 \\
\hline \multicolumn{3}{|c|}{ Condition of the umbilical stump/scar } \\
\hline Normal & 113 & 98.2 \\
\hline Changed & 1 & 0.8 \\
\hline
\end{tabular}


exclusive breastfeeding. Most NBs hadflushed skin and ten $(8.8 \%)$ had skin color suggestive of jaundice. The Kramer Table was used as a support for the investigation of jaundice during physical examination, since this tool is indicated to relate the dermal zone with levels of indirect bilirubin. Among NBs, $91.2 \%$ were classified in Zone 1, 6.4\% were classified in Zone 2 and $2.6 \%$ in Zone 3, the latter being considered a condition that needs greater attention, since neonates who presented this classification needed hospitalization for phototherapy. Another important factor evaluated in the consultation was the condition of the umbilical stump, as women, especially primiparous women, showed concern about its care.

During the nursing consultations carried out, it was observed that $92(80.7 \%)$ of the women had difficulties in caring for the NB, such as cleaning the umbilical stump, maintaining the quality/efficacy of breastfeeding, as well as difficulties with self-care with regard to hygiene of the surgical wound, identification of breast changes, beliefs about hypogalactia, and choice of adequate food for consumption during this period. The physical examination of the puerperal women also revealed alterations suggestive of wound infection in $17(14.9 \%)$ women, and breast changes in five $(4.4 \%)$. It was also found that eight $(7.0 \%)$ women needed to receive reinforcement as to the guidelines on how to make manual milking, and two (1.8\%) women were emotionally unstable because they reported difficulties in feeding due to the abrupt loss of appetite and difficulties to sleep even when the baby was sleeping. One of the women also mentioned that she felt like crying when looked at her baby, feeling guilty for the feelings they were experiencing. In view of the report of these women, psychological assessments were requested. Regarding the NBs' needs and behaviors, it was found that $103(90.4 \%)$ had general well-being and were released to go home and $11(9.6 \%)$ were referred for evaluation with a pediatrician due to changes found in the examination (umbilical stump and color suggestive of jaundice).

In addition, when women were asked if they had received guidance about the puerperium at any time before the nursing consultation, 76 (66.7\%) answered that they had not received it, and 38 $(33.3 \%)$ of the participants had already received guidance. The women said that the person who provided guidance, the main source of information, was the medical professional in the case of 20 $(52.7 \%)$ women, courses about pregnancy in the case of $14(36.8 \%)$ women, and nurses in the case of four $(10.5 \%)$ women.

\section{Discussion}

The results presented in this study showed characteristics of women and NBs who received care during puerperal consultations held in an institution, which supported listing priorities in the care of the motherchild binomial and in the elaboration of a flowchart for systematization of the puerperal nursing consultation.

Safe and harmless motherhood is a right of every woman during prenatal moments, childbirth and puerperium. It is essential to build a differentiated, humanized and qualified view of health care to mothers and NBs, considering social constructs such as social, economic, ethnic and gender inequalities. In this sense, it is necessary that health professionals, society and public policies recognize the diversity of true motherhood. 7

Thus, knowing the sociodemographic characteristics of women in the puerperal cycle can contribute to the guarantee of safe motherhood and quality care. A study showed that several factors are unfavorable for the practice of breastfeeding, including advanced maternal age, four or more residents at home, higher income, higher maternal education, and use of day care. 14 On the other hand, other authors inferred that maternal age below 20 years, low education, low family income, primiparity and the use of pacifiers were also associated with interruption of breastfeeding. 15

In view of the relevance and benefits inherent to exclusive breastfeeding for both mother and child, 15 18 it is important to investigate the influence of sociodemographic, physical and psychological characteristics on the practice of breastfeeding. 16-18

In view of this scenario, it isworth emphasizing the important role that health education has for women and families, 8,16 especially when performed in the puerperium. 4,18 It is necessary, therefore, that the educational action is not carried out unilaterally, that is, that only one person has the knowledge. The action must be linked to the demands of the puerperal women, valuing their knowledge, beliefs and values, respecting them as autonomous and coresponsible for their health in order to build shared knowledge. 8,16

Although the mother-child relationship is strengthened after the child's birth, in the time of pregnancy until the baby is born, it is common for women to create unrealistic fantasies and expectations about the period. ${ }^{19}$ From this perspective, a strengthened family base that can support the woman emotionally and assist her in the construction of her way of being a mother, which is peculiar to each 
woman, is essential. 18

In order to be successful in the practice of exclusive breastfeeding, it is necessary that health professionals involved in this assistance create a bond with the puerperal woman and value her beliefs and thoughts so as to establish a relationship of trust, understanding her experiences and sharing her difficulties, fears and anxieties. 19 These experiences or the lack of adequate information may lead to breast complications during lactation, such as breast engorgement and (more frequently) nipple trauma, which can culminate in premature weaning of the newborn. ${ }^{20,21}$ In the present study, difficulty in breastfeeding was associated with the presence of breast changes $(p<0.001)$. The main alteration observed was nipple trauma (fissures) and the most frequent complaint was pain during breastfeeding.

Other studies have shown that the main cause of pain during breastfeeding is the presence of lesions on nipples associated with positioning and incorrect lacth.22 Nipple trauma was the main cause of maternal anxiety and suffering in a study conducted in the state of Paraíba. ${ }^{21}$

The puerperal nursing consultation is an opportune moment for nurses to identify which factors may be related to difficulty in breastfeeding, either through listening to the woman, or through physical examination of the mother-child binomial. The examination makes it possible to identify the presence of flat, short or inverted nipples, oral defects in the child, prolonged non-nutritive sucking by the child, inappropriate use of breast pumps, inappropriate interruption of the child's suction when removed from the breast, use of creams and oils on the nipples, use of intermediate nipple protectors and continuous exposure to moisture. ${ }^{23}$

In this perspective, at the moment of the consultation, nurses should encourage appropriate breastfeeding practice, with emphasis on the importance of exclusive breastfeeding until the sixth month of life of the NB, with no need to offer water, tea or any other food.13 It is also essential to emphasize the benefits of breastfeeding: the low cost; the prevention of diarrhea in the NB; the aid in the development of the oral cavity that provides a better conformation of the hard palate and, consequently, correct alignment of the teeth; the protection of the woman against breast cancer;a greater affective bond between mother and child; and better quality of life for families. 23

When difficulty in breastfeeding is related to the presence of nipple trauma, professionals can implement strategies to relieve pain, as for example, adequate accommodation and variation in the posi- tion of the mother when breastfeeding; start of breastfeeding by the least injured breast; use of breast protectors that allow ventilation between the clothes and the breasts; sunbathing the breasts; complete emptying of the breasts; and manual milking to stimulate the milk ejection reflex, which will cause the child to suck the breast with less strenght. 23

For manual milking, massages in circular movements with the pulps of the index and middle fingers are recommended, in the nipple-areolar region, progressing to the most distant areas and intensifying in the most painful points. ${ }^{24}$ For the withdrawal of milk, the forefinger and thumb must be positioned at the limit of the areolar region to perform simultaneous light compression of the breast towards the chest and of the areolar region. 24

Another condition that requires the attention from nurses concerns the guidelines about the surgical incision. A surgical incision is often necessary, but it may expose the puerperal woman to the risk of infections and the need of use of antibiotics for prophylactic purposes in cesarean sections. 25 In this study, the physical examination showed that 17 (15.1\%) women had changes in the surgical incision (hyperemia, secretion, hyperemia and secretion, dehiscence).

When assessing the conditions of the surgical wound, nurses should advise women on how to clean it with soap and water, indicate the date for removing the stitches when the cesarean section is performed, advise on factors that facilitate healing, such as healthy eating, and those that do not favor healing, such as tobacco, alcohol and drug use. 25 When changes in the incision become visible, with the presence of secretion, it is necessary toevaluate its appearance (color and odor) and dehiscence. ${ }^{26} \mathrm{In}$ addition, with regard to self-care management, nurses should advise on the correct intake of antibiotics if they are to be used after hospital discharge. 26 When giving these instructions, other indirect aspects related to the surgical incision and healing can also be explored, such as body hygiene, routine activities and the return to sexual activity. 22

The reports of some women seen in the consultations showed emotional instability, which is a complex dimension of care in the puerperium. Factors such as altered family routine, hormonal and body changes, anxiety and insecurity in carrying out new tasks involving the care of the NB, changes in the quality of sleep and rest, discouragement, fatigue and $\operatorname{mood} 7,24$ should be explored by nurses through a clear and objective dialogue, 24 giving importance to the reports of mothers and supporting the coping 
with their new reality. In this sense, it is important that the health team is prepared to distinguish the transient and inherent emotional changes typical of this period from more serious conditions such as maternal sadness, baby blues, postpartum depression and puerperal psychosis. 24

Newborns were assessed for characteristics of birth, weight, spontaneous activity, breathing pattern, hydration status, eliminations, breastfeeding, and cephalocaudal physical examination, according to a technical manual aimed at prenatal and puerperal care ${ }^{24}$ with emphasis on skin color (pallor, jaundice and cyanosis) and conditions of the umbilical stump, as these aspects are of the interest of women during consultations. The evaluation of skin color showed that $8.8 \%$ of newborns had signs of neonatal jaundice. When evaluated by the Kramer Table, three (2.6\%) of the newborns were classified as being in Zone 3 and, after evaluated by a physician, they were referred to phototherapy, indicating a condition requiring greater attention.

Neonatal jaundice is a common clinical condition that occurs in approximately $80 \%$ of births. It can have a physiological cause, when its remission occurs within a few days after birth, or pathological, when it is necessary to start treatment with phototherapy because if left untreated, it can cause severe neurological injuries. 27 The Kramer table is a simple and low-cost form used in cases of suspected neonatal jaundice and that can assist nurses during puerperal consultations. However, the diagnosis of jaundice must be confirmed by the quantification of blood bilirubin through laboratory methods because the visual assessment alone can be influenced by characteristics of the NB (dark or light colored skin), anemia, prematurity and environmental factors such as lack of adequate lighting at the moment of the physical examination. 27

Neonatal jaundice can be prevented through exclusive breastfeeding 24 which, in turn, also contributes to the adequate weight gain of the newborn. ${ }^{23}$ In this study, most babies were in exclusive breastfeeding, an important aspect to be encouraged in nursing consultations through words of encouragement to mothers. 23

In relation to the umbilical stump, only one NB presented it altered. This, however, does not eliminate the need for attention and intervention of nurses because the umbilical stump is the area of the NB that is most susceptible to colonization and proliferation of microorganisms, with risk of neonatal omphalitis, sepsis and tetanus. It is, therefore, essential to advise puerperal women and their families on how to keep the umbilical stump clean and dry. To this end, alcohol $70 \%$ must be used to clean it and to accelerate the mummification and fall process. Alcohol should be applied to the base of the stump and throughout its extension with the aid of a flexible cotton swab and this must be made after the NB's bath and after diaper changes. ${ }^{28}$ The vaccination status of the puerperal woman against tetanus has also to be checked. In case of having not received or completed the scheme recommended by the $\mathrm{MOH}$, it must be resumed immediately in order to promote passive immunization of the NB. ${ }^{24}$ In this perspective, guidelines on the child's vaccination schedule and on the neonatal heel prick tests hould also be addressed. ${ }^{7}$

When analyzing data about the condition of the surgical incision in women and of the umbilical stump in NBs, more abnormalities were observed in women's surgical incision than in NBs' umbilical stump. These findings suggest that there may have been a transfer of care from women to their babies.

The nursing evaluations and guidelines given during consultations, initially, occurred through embracement, active listening to doubts and needs presented by the puerperal women, conversation about how were the days after hospital discharge, favoring the interaction between patient and professional. This space for dialogue and active listening was fundamental to allow puerperal women to expose their doubts, symptoms, feelings about the moments experienced, helping the researcher to learn about the family/social context in which the puerperal women were inserted. The majority of women reported that they had not been instructed prior to the puerperal consultation and, among those who received guidance, the main source was the physician. These results may be due to the population attended at this institution and the lack of knowledge in relation to the nurses' areas of activity. In the institution where this study was carried out, there is a frequent flow of puerperal women with their NBs seeking care in the institution's Emergency Service. Thus, this gap can support new studies and encourage nurses to seek ways to establish links with women so as to expand promotion and prevention practices aimed at maternal and child health.

The physical examination ofmothers and NBs followed guidelines contained in the MOH's Technical Manual of Prenatal and Puerperal Care. ${ }^{7}$ Nursing guidelines were given after identifying the changes presented in the physical examination and, when necessary, the mother-child binomial was referred to evaluation by other professionals (psychologist, pediatrician, gynecologist) part of the 
team at the institution. However, it is noteworthy that the health team, especially the nursing team, can contribute to guide women throughout the pregnancy-puerperium cycle and not only in the puerperium.

In order to contribute to the direction of nursing actions, a care flow chart was elaborated to be used in this study, in the puerperal nursing consultation, that met the needs of the studied population. We chose to represent this service through flowcharts due to the convenience of a quick and effective visualization of the steps to be followed.

The researchers' experience and aspects related to women in the puerperium and to the NBs, and those subject to nursing action through puerperal consultations were considered at the moment of preparing the care flow chart. As discussed in the stage of characterization of this study, the main aspects that stand out are: breastfeeding practice; breast assessment and identification of complications; evaluation of the surgical wound and guidance on how to care for it; clinical evaluation of the NB and; guidance on how to care for the NB.

The graphical construction of the chart was based on an orientation guide for the construction of nursing care protocols of the Regional Nursing Council of the state of São Paulo.29 (Figures 1 and 2).

The results of this study indicate ways to improve the structuring and implementation of puerperal consultations in the service studied and reinforce the need to provide guidance during this period through prenatal consultations. Although the study presents as a limitation the small number of women who returned to attend puerperal consultations, composing a small sample in this investigation, it is assumed that this fact may be due to several aspects, such as the culture of medicalization, the compartmentalized care, and the preference of women to receive puerperal consultations with physicians, overestimating this professional class, which is sometimes due to lack of knowledge of the nurses' areas of activity, and insecurity of being assisted by nurses, as well as the deficit of sensitivity and embracement of women during prenatal care.

This study identified that the main complaints and problems of women in the puerperium relate to the practice of breastfeeding, care for the NB, emotional state and family support. In general, these problems are related to the sociocultural and family environment in which women are inserted. In this sense, adapting the assistance to their beliefs - in order to achieve success when it comes to the guidelines offered in prenatal care, pregnancy courses, and puerperal consultations - is a challenge for nurses. The knowledge of the profile of womenassisted at the site of the present study made it possible to create a flowchart according to the women's main needs to be used at puerperal nursing consultations in a systematic way for the assessment of the mother-child binomial with multidisciplinary support.

It is hoped, therefore, that this study may contribute to a better understanding of nursing students and professionals about the needs and expectations presented by these women and also exercise their professionso as to satisfy this clientele and prevent complications.

\section{Authors' contribution}

Puglas LS participated in the conception, design, and collection, analysis and interpretation of data. Silveira LM and Mendes TJM did a critical review of the intellectual content of the manuscript. Stabile AM participated in the supervision at the conception, design, and analysis of results. All authors reviewed and approved the final version of the article. 


\section{Figure 1}

Nursing consultation flowchart: evaluation of the puerperal woman.

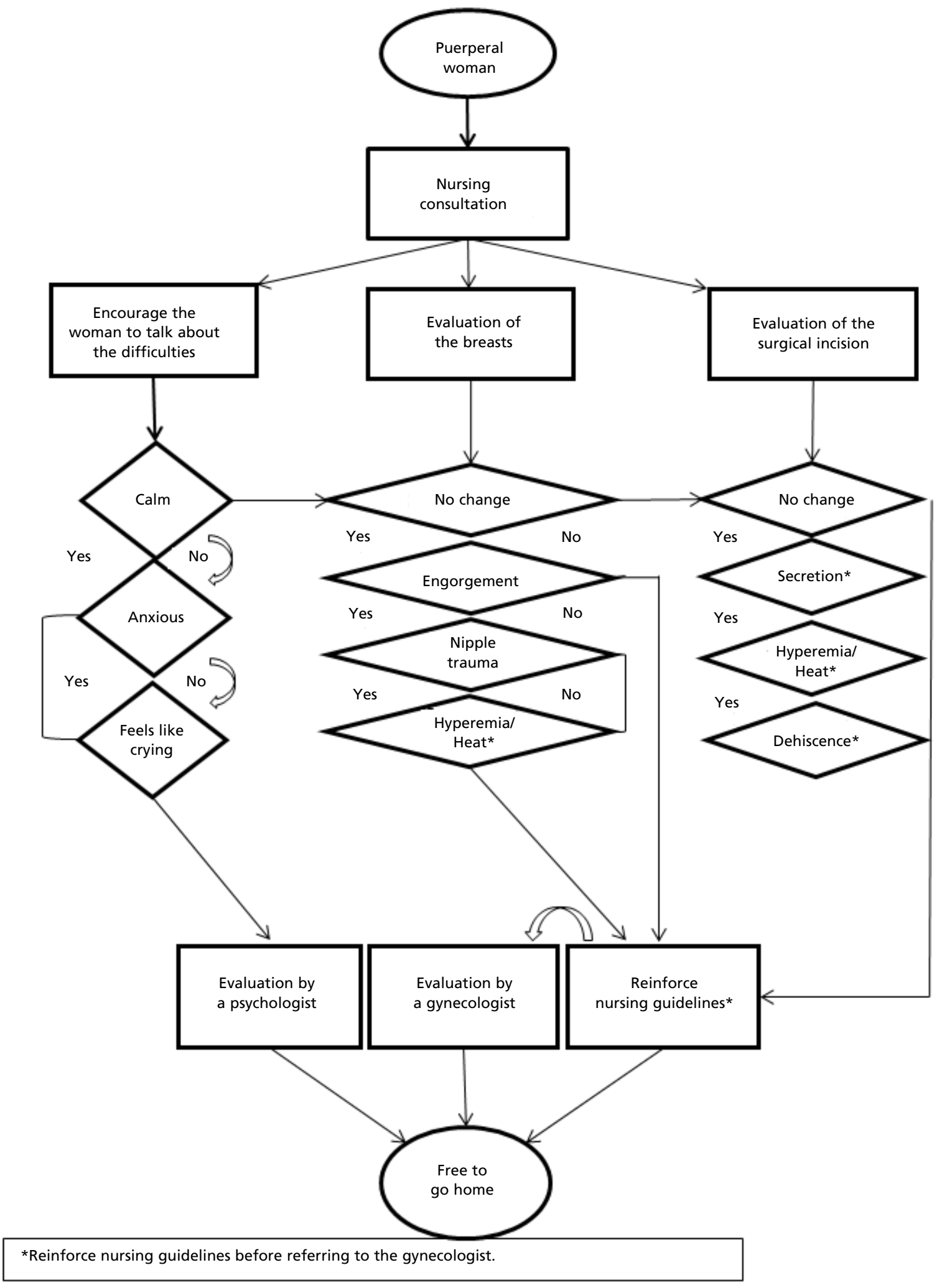




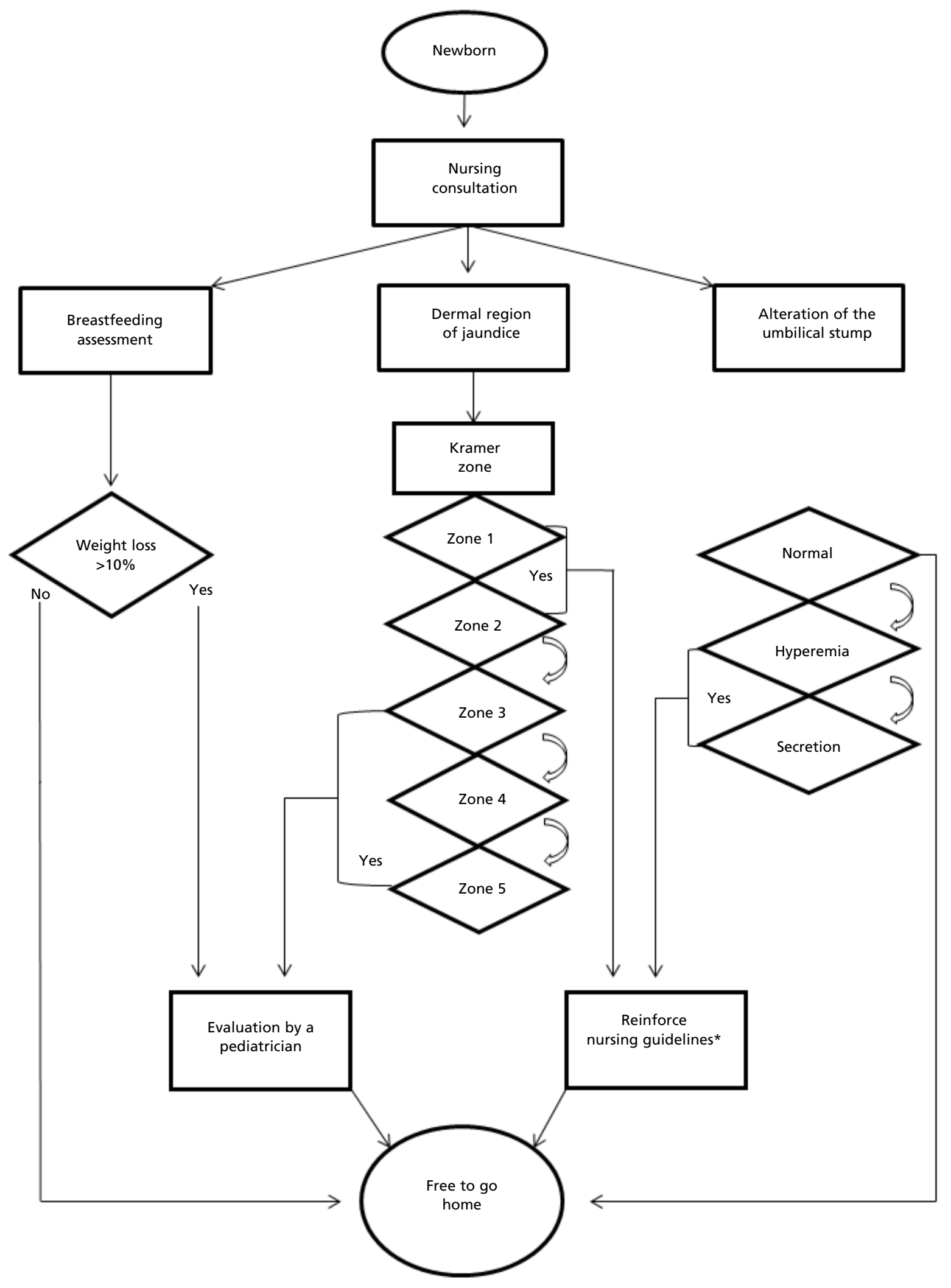




\section{References}

1. Strapasson MR, Nedel MNB. Puerpério imediato: desvendando o significado da maternidade. Rev Gaúcha Enferm. 2010; 31(3): 521-8.

2. Maldonado MT. Psicologia da gravidez: parto e puerpério. 16 ed. São Paulo: Saraiva; 2000. p. 30-45.

3. Rezende J, Montenegro CAB. Obstetrícia Fundamental. 14 ed. Rio de Janeiro: Guanabara Koogan, 2018. 1975 p.

4. Andrade RD, Santos JS, Maia MAC, Mello DF. Fatores relacionados à saúde da mulher no puerpério e repercussões na saúde da criança. Esc Anna Nery. 2015; 19 (1): 181-6.

5. Brasil. Ministério da Saúde. Secretaria de Atenção à Saúde. Departamento de Ações Programáticas Estratégicas. Política nacional de atenção integral à saúde da mulher: princípios e diretrizes / Ministério da Saúde, Secretaria de Atenção à Saúde, Departamento de Ações Programáticas Estratégicas. - Brasília, DF; 2004. 82 p.

6. Cassiano AN, Araújo MG, Holanda CSM, Costa RKS. Percepção de enfermeiros sobre a humanização na assistência de enfermagem no puerpério imediato. Rev Pesq Cuid Fundam. 2015; 7 (1): 2051-60.

7. Brasil. Ministério da Saúde. Secretaria de Atenção à Saúde. Departamento de Ações Programáticas Estratégicas. Área Técnica de Saúde da Mulher. Pré-natal e Puerpério: atenção qualificada e humanizada- Manual técnico. Brasília, DF; 2006, 163p. Disponível em: http://bvsms.saude.gov.br/bvs/ publicacoes/manual_pre_natal_puerperio_3ed.pdf

8. Dodou HD, Oliveira TDA, Oriá MOB, Rodrigues DP, Pinheiro PNC, Luna IT. Educational practices of nursing in the puerperium: social representations of puerperal mothers. Rev Bras Enferm. 2017; 70 (6): 1250-8. D

9. Neves BR, Silva TS, Gomes DR, Mattos MP, Mendes ACCS, Gomes DR. Intercorrências mamárias relacionadas com à amamentação: uma revisão sistemática. Rev Ciênc Saúde Oeste Baiano-Hígia. 2016; 1 (2): 58-73.

10. Lima GMM, Teles HL, Alcântara PPT, Moreira MRL, Pinto AGA, Marinho MNASB, Araújo AF, et al. Nursing Assistance At The Puerperium: Integrative Review Int Arch Med. 2017; 10 (25): 1-10.

11. Guerreiro EM, Rodrigues DP, Queiroz ABA, Ferreira MA Educação em saúde no ciclo gravídico-puerperal: sentidos atribuídos por puérperas. Rev Bras Enferm. 2014; 67 (1): 13-21

12. Angelo BHB, Brito RS. Consulta puerperal: O que leva as mulheres a buscarem essa assistência?. Rev Rene. 2012; 13 (5): 1163-70

13. Skupien SV, Ravelli APX, Acauan LV. Consulta puerperal de enfermagem: prevenção de complicações mamárias. Cogitare Enferm. 2016; 21 (2): 01-06

14 Pereira-Santos M, Santana MS, Oliveira DS, Nepomuceno Filho RA, Lisboa CS, Almeida LMR, Gomes DR, Queiroz VAO, Demétrio F, Oliveira AM. Prevalência e fatores associados à interrupção precoce do aleitamento materno exclusivo: metanálise de estudos epidemiológicos brasileiros. Rev Bras Saúde Mater Infant. 2017; 17 (1): 59-67.
15. Wenzel D; Souza SB. Fatores associados ao aleitamento materno nas diferentes regiões do Brasil. Rev Bras Saúde Matern Infant. 2014; 14 (3): 241-9.

16. Souza SA, Araújo RT, Teixeira JRB, Mota TN. Aleitamento materno: fatores que influenciam o desmame. Rev Enferm UFPE. 2016; 10 (10): 3806-13.

17. Catafesta F, Zagonel IPS, Martins M, Venturini KK. A amamentação na transição puerperal. Esc Anna Nery Rev Enferm. 2009; 13 (3): 609-16.

18. Gutman L. A maternidade e o encontro com a sua própria sombra. 11 ed.; tradução Luis Carlos Cabral, Mariana Laura Corrullón. Rio de Janeiro: BestSeller, 2017, p. 91-107p.

19. Batista KRA, Farias MCAD, Melo WSN. Influência da assistência de enfermagem na prática da amamentação no puerpério imediato. Saúde Debate. 2013; 37 (96): 130-8

20. Oliveira CS, Locca FA, Carrijo MLR, Garcia RATM. Amamentação e as intercorrências que contribuem para o desmame precoce. Rev Gaúcha Enferm. 2015; 36 (Esp): 1623 .

21. Amaral LJX, Sales SS, Carvalho DPSRP, Cruz GKP Azevedo IC, Ferreira Jr MA. Fatores que influenciam na interrupção do aleitamento materno exclusivo em nutrizes. Rev Gaúcha Enferm. 2015; 36 (Spe): 127-34.

22. Figueiredo JV, Fialho AVM, Mendonça GMM, Rodrigues DP, Silva LF. A dor no puerpério imediato: contribuição do cuidado de enfermagem. Rev Bras Enferm. 2018; 71 (Suppl. 3): 1343-50

23. Brasil. Ministério da Saúde. Secretaria de Atenção à Saúde. Departamento de Atenção Básica. Saúde da criança: aleitamento materno e alimentação complementar [Internet]. Caderno de Atenção Básica, n. 23. Brasília, DF; 2015 [acesso em 21 abr 2018]. Disponível em: http://bvsms.saude.gov.br/bvs/publicacoes/saude_crianca_a leitamento_materno_cab23.pdf

24. São Paulo (Estado). Secretaria da Saúde. Coordenadoria de Planejamento em Saúde. Assessoria Técnica em Saúde da Mulher. Atenção a gestante e à puérpera no SUS-SP: manual técnico do pré-natal e puerpério/ organizado por Karina Calife, Tania Lago, Carmem Lavras- São Paulo. 2010: SES/SP: 234. Documento em formato eletrônico. Disponível em: http://www.portaldaenfermagem.com.br/ downloads/manual-tecnico-prenatal-puerperio-sus.pdf.

25. Petter CE, Farret TCF, Scherer JS, Antonello VS. Fatores relacionados a infecções do sítio cirúrgico após procedimentos obstétricos. Scientia Medica (Porto Alegre). 2013; 23 (1): 28-33.

26. Cunha MR, Padoveze MC, Melo CRM, Nichiata LYI. Identificação da infecção de sítio cirúrgico pós-cesariana: consulta de enfermagem. Rev Bras Enferm. 2018; 71 (Supl. 3): 1395-1403.

27. Prada EMG. Hiperbilirrubinemia neonatal. Rev Soc Bol Ped]. 2005; 44 (1): 26-35.

28. Brasil. Atenção à saúde do recém-nascido: guia para os profissionais de saúde. Brasília, DF; 2011. 194 p. 
29. Pimenta CAM, Pastana ICASS, Sichieri K, et al. Guia para construção de protocolos assistenciais de enfermagem. COREN $1^{\text {a }}$ versão: São Paulo, 2012-2014 [acesso em 09 Out 2017]; 32-3. Disponível em: http://pesquisa.bvsalud. org/portal/resource/pt/biblio-837122.

Received on March 7, 2018

Final version presented on August 29, 2019

Approved on December 19, 2019 